\title{
Sınıf Öğretmeni Adaylarının Türkçe Öğretimi Yeterliklerinin Çeşitli Değişkenler Açısından Analizi*
}

\author{
Yahya Han Erbaş ${ }^{1}$
}

Type/Tür:

Research/Araştırma

Received/Geliş Tarihi: October

4/ 4 Ekim 2020

Accepted/Kabul Tarihi:

January 6/ 6 Ocak 2021

Page numbers/Sayfa No: 867 -

885

Corresponding

Author/İletişimden Sorumlu

Yazar: yahyahan@gmail.com

\section{$\checkmark$ iThenticate}

This paper was checked for plagiarism using iThenticate during the preview process and before publication. / Bu çalışma ön inceleme sürecinde ve yayımlanmadan önce iThenticate yazılımı ile taranmıştır.

\section{Copyright $@ 2017$ by}

Cumhuriyet University,

Faculty of Education. All rights reserved.

\section{Öz}

Yeterlik, öğretmenlik mesleğini etkili ve verimli bir biçimde yerine getirebilmek için sahip olmaları gereken bilgi, beceri ve tutumlar olarak tanımlanmaktadır. $\mathrm{Bu}$ araştırmada sınıf öğretmeni adaylarının Türkçe öğretimi konusunda yeterliklerinin farklı değişkenlerle ile olan ilişkisinin incelenmesi amaçlanmıştır. Araştırmanın örneklem grubunu Temel Eğitim Bölümü Sınıf Öğretmenliği Anabilim Dalında öğrenim gören toplam 274 öğretmen adayı oluşturmaktadır. Örneklem seçiminde amaçlı örnekleme yöntemine başvurulmuştur. Örneklem seçiminin bu şekilde tercih edilme nedeni Türkçe öğretimi dersini tamamlamış farklı sınıf seviyelerinde yer alan öğretmen adaylarının Türkçe öğretimine dair yeterliklerinin bilinmek istenmesidir. Araştırmada sınıf öğretmen adaylarının Türkçe Öğretimi yeterliklerine ilişkin görüşlerinin belirlenmesi için Yeşiloğlu ve Özer (2017) tarafından geliştirilen "Türkçe Öğretimi Yeterliliği Ölçeği" kullanılmıştır. Araştırmadan elde edilen bulgulara göre Türkçe öğretimi dersini tamamlamış sınıf öğretmeni adaylarının Türkçe öğretimine dair yeterlik düzeylerini yeterli gördükleri belirlenmiştir. Farklı sınıf seviyelerinde bulunan Türkçe Öğretimi dersini tamamlamış sınıf öğretmeni adaylarının, Türkçe öğretimine dair yeterlikleri arasında anlamlı farklar ortaya çıkmıştır. Sınıf öğretmeni adaylarının Türkçe öğretimine dair yeterlikleri ile genel not ortalamaları değişkeni arasında anlamlı bir farklılık tespit edilmemiştir. Ancak puan ortalamalarına bakıldığında 2.5 ve altı genel not ortalamasına sahip öğretmen adaylarının Türkçe öğretimine dair daha düşük yeterliliğe sahip oldukları anlaşılmaktadır. Sınıf öğretmenliği lisans eğitimi boyunca öğretmen adaylarının okudukları kitap sayısının Türkçe öğretimi yeterlikleri üzerinde etkisi olduğunu göstermiştir. Sınıf öğretmenliği bölümünü isteyerek tercih eden öğretmen adaylarının Türkçe öğretimi yeterlik algılarının, istemeden yerleşen öğretmen adaylarına göre daha yüksek olduğu sonucuna varılmıştır.

Anahtar Kelimeler: Sınıf öğretmeni adayları, Türkçe öğretimi, özel alan yeterlikleri, öğretmen eğitimi, yenilenmiş öğretmen eğitimi programlar1

\section{Suggested APA Citation/Önerilen APA Atıf Biçimi:}

Erbaş, Y.H. (2021). Sınıf öğretmeni adaylarının Türkçe öğretimi yeterliklerinin çeşitli değişkenler açısından analizi. Cumhuriyet International Journal of Education, 10(2), 867-885. http://dx.doi.org/10.30703/cije.804935

\footnotetext{
*Bu çalışmaya ait bazı bulgular, 25-28 Nisan 2019 tarihinde Rize'de düzenlenen 12. Uluslararası Eğitim Araştırmaları Kongresi'nde sunulmuştur.

1 Dr. Öğr. Üyesi, Çanakkale Onsekiz Mart Üniversitesi, Eğitim Fakültesi, Eğitim Bilimleri Bölümü, Çanakkale/Türkiye

Assist. Prof. Dr., Canakkale Onsekiz Mart University, Faculty of Education, Department of Educational Sciences, Canakkale/Turkey

e-mail: yahyahan@gmail.com ORCID ID: https:// orcid.org/0000-0003-0802-4536
} 


\title{
Turkish Language Teaching Proficiency of Preservice Primary School Teachers: An Analysis Incorporating Multiple Variables
}

\begin{abstract}
Teaching proficiency is defined as having the prerequisite knowledge, skills, and Teaching proficiency is defined as having the prerequisite knowledge, skills, and attitudes needed to fulfill the requirements of teaching in an effective and efficient manner. This study, therefore, seeks to examine preservice primary school teachers' (PPSTs)' Turkish language teaching proficiencies according to multiple variables. The sample group was composed of 274 preservice teachers enrolled in the Faculty of Education, Department of Primary School Teaching. Purposeful sampling was employed to select participants for inclusion in the study group because it was aimed to determine the Turkish language teaching proficiency levels of PPSTs of different grade levels who had successfully completed Turkish teaching education class. Turkish Language Teaching Proficiency Scale developed by Yeşiloğlu and Özer (2017) wad administered to measure how PPSTs perceived their proficiency levels in teaching Turkish. The findings obtained reveal that those PPSTs who have completed their Turkish language teaching class may be considered adequately proficient in Turkish language education. Still, meaningful differences did appear in the Turkish language teaching proficiency levels of PPSTs by grade level, regardless of the fact that they had all completed the same class. However, although no meaningful difference was found to exist between PPSTs' GPAs and Turkish language teaching proficiency levels, those PPSTs whose GPA was 2.5 or lower had lower Turkish language teaching proficiency levels. Throughout their undergraduate education, the number of books that PPSTs read has an influence on how proficient they are at teaching Turkish. Furthermore, the differences in how PPSTs perceived their own Turkish language teaching proficiency levels differed greatly between those teachers who were intrinsically driven to study primary school education and those who chose it because they were obligated to do so.
\end{abstract}

Keywords: Preservice primary school teachers, Turkish language teaching, special field proficiency, teacher education, renewed teacher education programs

\section{Giriş}

Eğitim-öğretim faaliyetlerinin nitelikli bir şekilde devam edebilmesinde öğretmen niteliklerinin etkisinin büyük olduğu yadsınamaz bir gerçektir (Sünbül, 2011). Tarihsel süreç içerisinde öğretmenin rollerinde ve sorumluluklarında zamanın gerekliliklerine göre çeşitli değişimler olmasına rağmen, öğretmenin eğitim-öğretim hizmetleri içerisindeki önemi hiçbir zaman azalmadığ1 gibi her geçen gün önemi daha da artmaktadır (Akyol, 2016; Baştuğ, 2016; Odabaşı, Çoklar, kıyıcı ve Akdoğan, 2005; Onan ve Kan, 2018; Özer ve Gelen, 2008). Buna bağlı olarak öğretmen yeterliklerinin öğrencinin başarısını dolaylı yada doğrudan etkilediğini gösteren, öğretmenlik mesleğini yapabilmek için sahip olunması gereken mesleki ve pedagojik bilgilerin neler olduğunu analiz eden ulusal ve uluslararası çalışmalar bulunmaktadır (Buldu, 2014; Darling- Hammond, 2000; Gencel, 2013; Goe ve Sticker, 2008; Jaquith, Mindich, Wei ve Darling-Hammond, 2010). Öğretmen niteliklerinde neler olması konusunda yetkili kurum ve kuruluşlarca da çeşitli tarihlerde çalışmalar yürütülmüştür ve belli aralıklarla bu konu hakkında çalışmalar yapılmaktadır. Bu çalışmalardan biri de 2006 yılında YÖK, MEB, sivil toplum kuruluşları ve diğer alan uzmanları tarafından oluşturulan "Öğretmenlik Mesleği Genel Yeterlikleri” (MEB, 2006) çalışmasıdır. Öğretmen Yetiştirme ve Geliştirme Genel Müdürlüğü (ÖYGM) tarafından yayınlanan "Öğretmenlik Mesleği Genel Yeterlikleri" belgesine göre 
öğretmen yeterlikleri “öğretmenlik mesleğini etkili ve verimli bir biçimde yerine getirebilmek için sahip olmaları gereken bilgi, beceri ve tutumlar" (s.4) olarak tanımlanmaktadır. Belli aralıklarla güncellenerek öğretmenlerin hangi alanlarda ne tür bilgiye ve becerilere sahip olması gerektiği belirlenmektedir. Aynı şekilde, MEB tarafından genel alan yeterlikleriyle uyumlu bir şekilde değerlendirilmesi gereken "Özel Alan Yeterlikleri" geliştirilmiş olup, ilkokul ortaokul ve lise seviyelerinde görev alacak öğretmenlerin eğitim aldıkları alan özelinde hangi yeterliklere sahip olması gerektiği belirlenmiştir. Bu özel alan yeterlikleri (i)yeterlik alanı, (ii)kapsam, (iii)yeterlikler ve (iv)performans göstergeleri olmak üzere dört farklı başlık altında toplanmışlardır (MEB, 2017). Branşlara dair özel alan yeterlikleri incelendiğinde, çalışma şartları gereği birçok dersten sorumlu olan sınıf öğretmenlerine hedef olarak konulan özel alan yeterliklerinin, diğer branş öğretmenlerine göre daha fazla olduğunu görmekteyiz. Sınıf öğretmenlerinin özel alan yeterliklerinin diğer branşlara göre fazla olması bir iş yükü oluşturmakta, bu da mesleki yeterliklerine yansımaktadır (Cerit ve Özdemir, 2015).

Birçok dersin işleyişinden sorumlu olacak olan sınıf öğretmeni adaylarının, vermekle yükümlü olacakları derslere dair almış oldukları eğitimi değerlendiren, öğretmenlik mesleğine karşı tutumlarını ve mesleki yeterliklerini inceleyen çalışmalara alanyazında sıklıkla karşılaşmaktayız (Babaoğlan ve Yılmaz, 2010; Bektaş, Aydın ve Ayvaz, 2015; Bektaş, Ayvaz-Can ve Çalıkoğlu, 2019; Berkant ve Ekici, 2007; Çapri ve Çelikkaleli, 2008; Çelik, Yorulmaz ve Çokçalışkan, 2019; Çetin, 2018; Donmuş vd. 2017; Güven ve Ersoy, 2007; Hacıömeroğlu ve Şahin-Taşkın, 2010; Kahramanoğlu ve Ay, 2013; Kara, Demir, Arcagök ve Şahin, 2018; Şahin, 2011; Şişman ve Acat, 2003; Taşgın ve Sönmez, 2010). Bu çalışma özelinde incelediğimizde de sınıf öğretmenlerinin Türkçe öğretimi yeterliklerine dair yapılan çalışmalarda alanyazında karşımıza çıkmaktadır (Erdem ve Bayraktar, 2019; Evren-Acar, 2010; Gök ve Erdoğan, 2009; Karasakaloğlu ve Saracaloğlu, 2009; Okur, 2011; Özdemir ve Erdoğan, 2017; Yeşiloğlu ve Özer, 2017). Aynı şekilde bu akademik çalışmalar içerisinde, sınıf öğretmeni adaylarının Türkçe öğretimine dair yeterliklerini inceleyen çalışmalarla da karşılaşmaktayız. Örneğin, Erdem ve Bayraktar (2019) yaptıkları araştırmada sınıf öğretmeni adaylarının Türkçe öğretimi noktasında "sınıf yönetimi, katılım sağlama, iletişim becerileri, soru-cevap etkinlikleri" (s.23) konularında kendilerini yeterli hissettikleri, fakat "etkili öğretim yöntemleri ve günlük hayatla konu arasında bağlantı kurma" (s.23) alanlarında kendilerini geliştirmeleri gerektiği sonucuna ulaşmışlardır. Bu bulgulara ek olarak, Gök ve Erdoğan (2009)'ın araştırma sonuçlarına göre sınıf öğretmeni adayları, Türkçe öğretimi konusunda kendilerini daha çok bu ders için kullanılması önerilen doğru ölçme ve değerlendirme yöntem ve tekniklerini kullanmada eksik hissettiklerini söylemişlerdir. Bunlardan farkl1 olarak, Yeşiloğlu ve Özer (2017), sınıf öğretmeni adaylarının "bir yılda okunan kitap sayısı, akademik başarı ve bölüme isteyerek gelme" (s.863) değişkenlerine göre Türkçe öğretimi konusunda kendilerini yeterli gördükleri sonucuna ulaşmışlardır.

Eğitim sisteminde ve öğretmen yetiştiren kurumların programlarında sürekli bir değişimin olduğu günümüzde öğretmen olmak isteyen adayların yeterliklerinin belli aralıklarla değerlendirilmesi, bu mesleğe ne oranda hazır olduklarını görmek adına önemlidir. İlkokul ders programlarında en büyük paya sahip Türkçe dersinin başarılı bir şekilde işlenmesinde sınıf öğretmenlerinin 
yeterliklerinin belirlenmesi, bu dersin amaçları doğrultusunda öğretilmesinde ne gibi eksiklerinin olduğunun belirlenmesi gereklidir (Acar, 2010).

\section{Yeni Öğretmen Yetiştirme Lisans Programları}

Bilindiği üzere, Yükseköğretim Kurulu (YÖK) 30 Mayıs 2018 tarihli güncellenen, eğitim fakültelerinde yer alan bölümlerin yeni programlarını yayınlamıştır. Eski programların güncellenmesine;

- Daha önceki güncelleme çalışmalarında ortaöğretim alan öğretmenliklerinin göz ardı edildiklerini,

- Üniversiteler arası AKTS konularında sorunlar olduğunu,

- MEB tarafindan okullarda okutulan bazı ders içeriklerinin değiştirilmesine bağlı olarak öğretmenlik meslek bilgisine dair alanlarda değişiklik yapılmasının gerektiğini,

- Bologna sürecine uyum ve akreditasyon çalışmalarına bağlı olarak seçmeli ders havuzlarının oluşturulması ihtiyacının ortaya çıkmasını,

- Evrensel, milli ve kültürel değerleri tanıyan, araştırmacı öğretmen modeli yetiştirme gerekliliğin oluşmasını gerekçe olarak gösterilmiştir. (s.12-13)

$\mathrm{Bu}$ yeni düzenleme incelendiğinde, sınıf öğretmenliği programinin en çok değişime uğrayan üçüncü program olduğunu görmekteyiz. Yeni güncelleme ile ders saatlerinde 28 saatlik, toplam ders kredilerinde de 14 kredilik bir azalma vardir (YÖK, 2018). Bu ders ve kredi azalmalarının yanı sıra, derslerin okutuldukları yarıyıllarda da değişimlerin olduğunu görmekteyiz. Önceki yıllarda beşinci yarıyılda okutulan İlkokuma ve Yazma öğretimi dersinin üçüncü yarıyıla, altıncı yarıyılda okutulan Türkçe Öğretimi dersinin dördüncü yarıyıla kaydırılmıştır. 2019-2020 eğitim-öğretim yılında hem üçüncü sınıfta okuyan sınıf öğretmeni adayları hem de ikinci sınıfta okuyan öğretmen adayları yukarıda belirtilen bu iki dersi beraber almak durumunda kalmışlardır.

Yukarıda da değinildiği üzere, öğretmen eğitiminde değişimlerin yaşandı̆̆ bir gerçektir. Bu değişimlerin öğretmen adaylarının üzerindeki etkileri ve ne kadar uyum gösterebildiğinin incelenmesi önemlidir. Eski ve yeni öğretmen yetiştirme programlarına göre eğitim alan sınıf öğretmeni adaylarının, farklı sınıf seviyelerinde Türkçe Öğretimi dersini almış olmaları ve bu değişikliğe bağlı olarak ortaya çıkabilecek yeterliklerini etkileyen sebepleri karşılaştırma adına bu çalışma önem arz etmektedir.

Bu çalışmada 2019-2020 eğitim-öğretim yılında Çanakkale Onsekiz Mart Üniversitesi Eğitim Fakültesi, Temel Eğitim Bölümü, Sınıf Öğretmenliği Anabilim Dalı'nda öğrenim gören, program dahilinde almakla yükümlü olduğu, üç kredi ve beş AKTS değerindeki Türkçe Öğretimi dersini tamamlayan sinıf öğretmeni adaylarının, Türkçe öğretimi konusunda yeterliklerinin farklı değişkenlerle ile olan ilişkisinin incelenmesi amaçlanmıştır.

Bu bağlamda yapılan araştırmada şu sorulara yanıt aranmıştır;

1. Türkçe öğretimi dersini tamamlamış sınıf öğretmeni adaylarının Türkçe öğretimi yeterlikleri ne düzeydedir? 
2. Türkçe öğretiminin öğrenme alanlarına (konuşma, dinleme, okuma, yazma, görsel okuma ve sunu) göre sınıf öğretmeni adaylarının yeterlikleri ne düzeydedir?

3. Türkçe öğretimi dersini tamamlamış farklı sınıf seviyelerinde yer alan sınıf öğretmeni adaylarının Türkçe öğretimine dair yeterlikleri arasında anlamlı bir fark var midir?

4. Türkçe öğretimi dersini tamamlamış sınıf öğretmeni adaylarının genel not ortalamalarına göre Türkçe öğretimine dair yeterlikleri arasında anlamlı bir fark var midir?

5. Türkçe öğretimi dersini tamamlamış sınıf öğretmen adaylarının lisans eğitimi süresince okudukları ortalama kitap sayısına göre Türkçe öğretimine dair yeterlikleri arasında anlamlı bir fark var mıdır?

6. Türkçe öğretimi dersini tamamlamış sınıf öğretmen adaylarının öğrenim gördükleri bölüme yerleşmeyi isteme durumlarına göre Türkçe öğretimine dair yeterlikleri arasında anlamlı bir fark var mıdır?

\section{Araştırmanın Modeli}

\section{Yöntem}

$\mathrm{Bu}$ araştırmada sınıf öğretmeni adaylarının Türkçe öğretimine dair yeterliklerinin değerlendirilmesi amaçlanmaktadır. Bu amaç kapsamında, araştırmada betimsel tarama modeli kullanılmıştır. Bu model, araştırmaya katılan bireylerin özelliklerini ortaya koymayı amaç edinmiş bir süreçten oluşur (Büyüköztürk, Çakmak, Akgün, Karadeniz ve Demirel, 2016). Bu araştırma sınıf öğretmeni adaylarının Türkçe öğretimine dair yeterliklerini ortaya koymanın yanı sıra, yeterliklerinin öğrenim gördükleri programın sınıf seviyesi, not ortalamaları, lisans eğitimi süresince okudukları ortalama kitap sayısı ve eğitim aldıkları bölüme isteyerek yerleşme durumlarıyla olan ilişkisinin belirlenmesi de amaçlanmaktadır.

\section{Evren-Örneklem}

Araştırmanın evrenini 2019-2020 öğretim yılında Çanakkale Onsekiz Mart Üniversitesi Eğitim Fakültesinde öğrenim gören öğretmen adayları oluşturmaktadır. Araştırmanın örneklem grubunu ise, Temel Eğitim Bölümü Sınıf Öğretmenliği Anabilim Dalında öğrenim gören toplam 274 öğretmen adayı oluşturmaktadır. Örneklem seçiminde amaçlı örnekleme yöntemine başvurulmuştur. Belli ölçütler ve özellikleri taşıyan özel durumlarda bu ölçekleme tekniğinin kullanılması önerilmektedir (Büyüköztürk vd., 2016). Örneklem seçiminin bu şekilde tercih edilme nedeni Türkçe öğretimi dersini tamamlamış farklı sınıf seviyelerinde yer alan öğretmen adaylarının Türkçe öğretimine dair yeterliklerinin bilinmek istenmesidir. Bu kapsamda 76'sı $(\% 27,7)$ ikinci sınıf, 93'ü $(\% 33,9)$ üçüncü sınıf ve 105'i $(\% 38,3)$ son sınıf olmak üzere farklı sınıf seviyelerinde öğrenimlerine devam eden sınıf öğretmen adaylarına ölçeğin uygulanması gerçekleştirilmiştir.

\section{Veri Toplama Arac1}

Araştırmada sınıf öğretmen adaylarının Türkçe Öğretimi yeterliklerine ilişkin görüşlerinin belirlenmesi için Yeşiloğlu ve Özer (2017) tarafından geliştirilen “Türkçe Öğretimi Yeterlilik Ölçeği" kullanılmıştır. Ölçek Türkçe öğretiminin dinleme, konuşma, okuma, yazma ve görsel okuma/görsel sunu şeklindeki beş temel 
öğrenme alanına yönelik hazırlanmış 60 maddeden oluşmaktadır. Ölçekte olumsuz madde bulunmamaktadır. Beşli likert tipinde derecelendirilen ölçeğin Cronbach Alpha (a) güvenirlik katsayı değeri 0,98' dir.

\section{Verilerin Toplanması}

Araştırmanın verileri 2019-2020 öğretim yılı bahar döneminde toplanmıştır. Bizzat araştırmacı tarafından adaylara uygulanan ölçeğin doldurulmasının gönüllülük esasına dayalı olduğu, sonuçlarının sadece bilimsel amaçlı kullanılacağı belirtilmiştir. Ölçeğin nasıl doldurulacağı hakkında yönergeler verilmiştir. Ölçek için yaklaşık 30 dakika zaman ayrılmıştır.

\section{Verilerin Analizi}

Araştırma verilerinin değerlendirilmesinde SPSS 20.00 programı kullanılmıştır. Sınıf öğretmeni adaylarının Türkçe Öğretimi yeterliklerine ilişkin görüşlerinin belirlenmesinden elde edilen bulgular değerlendirilmiştir. Verilerin analizinde betimleyici sayısal değerleri ortaya koyabilmek için aritmetik ortalama ve standart sapma değerleri hesaplanmıştır. Ölçek 300 puan üzerinden değerlendirilmiştir. Araştırma bulgularında yer alan puan ortalamaları 1-1.80 puan arası çok yetersiz, 1.81-2.60 puan arası yetersiz, 2.61-3.40 arası kısmen yeterli, 3.41-4.20 aras1 yeterli ve 4.21-5.00 arası çok yeterli olarak değerlendirilmiştir.

Araştırmada toplanan verilerin normallik varsayımları test edilmiş, bu inceleme sonucunda verilerin normal dağılım göstermediği belirlenmiştir. Bu nedenle verilerin analizinde parametrik olmayan testlerden Mann Whitney U ve Kruskal Wallis testleri kullanılmıştır. Kruskal Wallis test sonucunda değişkenler arası farkın hangi gruptan olduğunu belirlemek için Tukey testi uygulanmıştır. Ayrıca bu araştırmada Cronbach Alpha güvenirlik katsayısı 0,96 olarak hesaplanmıştır.

\section{Bulgular}

Bu bölümde, sınıf öğretmeni adaylarının Türkçe öğretimine dair yeterliklerinin araştırılmasından elde edilen bulgular sunulmuştur.

Sınıf öğretmeni adaylarının Türkçe öğretimine dair yeterlik düzeyleri ile ilgili istatistiksel bilgiler Tablo 1'de sunulmuştur.

Tablo 1.

Sinı Öğretmeni Adaylarnın Türkçe Öğretimine Dair Yeterlik Düzeyleri

\begin{tabular}{cccccc}
\hline \multirow{2}{*}{$\begin{array}{c}\text { Türkçe öğretimine dair } \begin{array}{c}\text { En Yüksek } \\
\text { Puan }\end{array} \\
\text { yeterlik düzeyi }\end{array}$} & $\mathbf{N}$ & En Düşük Puan & $\bar{x}$ & SS \\
\cline { 2 - 5 } & 274 & 1,00 & 5,00 & 3,62 & 0,53 \\
\hline
\end{tabular}

Tablo 1'de sınıf öğretmen adayları Türkçe öğretimine dair yeterlik düzeylerini yeterli gördükleri belirlenmiştir $(\bar{x}=3,62)$. Ayrıca Türkçe öğretiminde sınıf öğretmeni adaylarının dinleme, konuşma, okuma, yazma, görsel (okuma-sunu) öğrenme alanlarına göre yeterlilikleri incelenmiştir, Tablo 2'de gösterilmiştir. 
Tablo 2.

Sınıf Öğretmeni Adaylarının Türkçe Öğretimine Dair Yeterlik Düzeylerinin Öğrenme Alanlarına Göre Incelenmesi

\begin{tabular}{lllll}
\hline Ölçek & Türkçe Dersi Alt Alanları & $\overline{\boldsymbol{x}}$ & \multicolumn{1}{c}{ SS } \\
\hline \multirow{4}{*}{$\begin{array}{l}\text { Türkçe } \\
\text { yeterlilik dügrzeyi }\end{array}$} & Dinleme & 3,55 & 0,64 \\
\cline { 2 - 4 } & Konuşma & 3,54 & 0,60 \\
\cline { 2 - 4 } & Okuma & 3,65 & 0,66 \\
\cline { 2 - 4 } & Yazma & 3,73 & 0,64 \\
\cline { 2 - 4 } & Görsel (Okuma-Sunu) & 3,63 & 0,73 \\
\hline
\end{tabular}

Tablo 2'de sınıf öğretmeni adaylarının tüm öğrenme alan becerileri bakımından Türkçe öğretimine dair yeterlik düzeylerini yeterli görmekte oldukları anlaşılmaktadır. Bununla birlikte adayların tüm öğrenme alanlarına dair puanların birbirine yakın olduğu görülmektedir. Ayrıca yazma öğrenme alanının en yüksek $(\bar{x}=3,73)$; konuşma öğrenme alanının ise en düşüuk $(\bar{x}=3,54)$ ortalamaya sahip olduğu görülmektedir.

Sınıf öğretmeni adaylarının Türkçe öğretimine dair yeterliklerinin sınıf seviyelerine göre karşılaştırılmasına yönelik Kruskal Wallis test sonuçları Tablo 3'te sunulmuştur.

Tablo 3

Sını Öğretmeni Adaylarının Sını Seviyelerine Göre Türkçe Öğretimine Dair Yeterlikleri

\begin{tabular}{lrccccc}
\hline Ölçek & $\begin{array}{l}\text { Sınıf } \\
\text { Seviyeleri }\end{array}$ & $\mathbf{N}$ & Sıra Ortalaması & $\mathbf{X}^{\mathbf{2}}$ & $\boldsymbol{p}$ & Anlamlı Fark \\
\hline Türkçe & 2.Sınıf & 76 & 115,23 & & & 2. sınıf-3.sınıf \\
Öğretimine & 3.Sınıf & 93 & 147,40 & 8,360 & 0,015 & 2. sınıf-4.sınıf \\
dair yeterlikler & 4.Sınıf & 105 & 144,85 & & & \\
\hline
\end{tabular}

Tablo 3'te Kruskal Wallis test sonuçlarına göre sınıf öğretmeni adaylarının Türkçe öğretimine dair yeterlikleri ile sınıf seviyesi değişkeni arasında anlamlı fark tespit edilmiştir $\left(X^{2}=8,360 ; p<0,05\right)$. Belirlenen anlamlı farklılı̆̆ın hangi gruplar arasında olduğunu belirlemek için yapılan Tukey testi sonuçlarından 2. sinıfta eğitim gören öğretmen adaylarının Türkçe öğretimine dair yeterliklerinin 3. ve 4. sınıf öğretmen adaylarına göre daha düşük seviyede olduğu ve aralarındaki farkın da anlamlı olduğu anlaşılmaktadır.

Sınıf öğretmeni adaylarının Türkçe öğretimine dair yeterliklerinin genel not ortalamasına göre karşılaştırılmasına yönelik Kruskal Wallis test sonuçları Tablo 4'te yer almaktadir.

Tablo 4'te Kruskal Wallis test sonuçlarına göre sınıf öğretmen adaylarının Türkçe öğretimine dair yeterlikleri ile genel not ortalamaları değişkeni arasında anlamlı bir farklılık tespit edilmemiştir $(p>0,05)$. Ancak puan ortalamalarına bakıldığında 2.5 ve altı genel not ortalamasına sahip öğretmen adaylarının Türkçe öğretimine dair daha düşük yeterliliğe sahip oldukları anlaşılmaktadır. 
Tablo 4

Sını Öğretmen Adaylarmın Genel Not Ortalamalarına Göre Türkçe Öğretimine Dair Yeterlikleri

\begin{tabular}{lccccc}
\hline Ölçek & Not Ortalaması & $\mathbf{N}$ & Sıra Ortalaması & $\mathbf{X}^{\mathbf{2}}$ & $\boldsymbol{p}$ \\
\hline Türkçe Öğretimine & 2.5 ve altı & 26 & 115,31 & & \\
dair yeterlikler & $2.5-3$ arası & 127 & 133,51 & 3,907 & 0,272 \\
& $3-3.5$ arası & 110 & 146,47 & & \\
& 3.5 ve üstü & 11 & 146,32 & & \\
\hline
\end{tabular}

Sınıf öğretmeni adaylarının Türkçe öğretimine dair yeterliklerinin adayların okudukları ortalama kitap sayısına göre karşılaştırılmasına yönelik Kruskal Wallis test sonuçları Tablo 5' te yer almaktadır.

Tablo 5

Sinıf Öğretmen Adaylarının Lisans Eğitimi Boyunca Okuduklan Ortalama Kitap Sayısına Göre Türkçe Öğretimine Dair Yeterlikleri

\begin{tabular}{lcccccc}
\hline Ölçek & $\begin{array}{c}\text { Okunan Kitap } \\
\text { Sayısı }\end{array}$ & $\mathbf{N}$ & $\begin{array}{c}\text { Sıra } \\
\text { Ortalaması }\end{array}$ & $\mathbf{X}^{\mathbf{2}}$ & $\boldsymbol{p}$ & Anlamlı Fark \\
\hline Türkçe & 15 kitap ve altı & 78 & 127,96 & & & $1-3$ \\
Öğretimine dair & 15-30 kitap arası & 92 & 125,03 & 8,890 & 0,012 & $2-3$ \\
yeterlikler & 30 kitap ve üstü & 104 & 155,69 & & & \\
\hline
\end{tabular}

Tablo 5'te Kruskal Wallis test sonuçlarına göre sınıf öğretmen adaylarının Türkçe öğretimine dair yeterlikleri ile lisans eğitimi boyunca okudukları ortalama kitap sayısı değişkeni arasında anlamlı fark tespit edilmiştir $\left(X^{2}=8,890 ; p<0,05\right)$. Belirlenen anlamlı farklılığın hangi gruplar arasında olduğunu belirlemek için yapılan Tukey testi sonuçlarından 30 kitap ve daha fazla kitap okuyan sınıf öğretmen adaylarının daha az kitap okuyan öğretmen adaylarına kıyasla Türkçe öğretimine dair yeterliklerinin daha yüksek seviyede olduğu ve aralarındaki farkın da anlamlı olduğu anlaşılmaktadır.

Sınıf öğretmeni adaylarının Türkçe öğretimine dair yeterliklerinin öğrenim görülen bölüme yerleşmeyi isteme durumlarına yönelik karşılaştırılmasına yönelik Mann Whitney-u testi sonuçları Tablo 6' da gösterilmektedir.

Tablo 6

Öğretmen Adaylarnnın Öğrenim Gördükleri Bölüme Yerleşmeyi İsteme Durumlarına Göre Türkçe Öğretimine Dair Yeterlikleri

\begin{tabular}{llccccc}
\hline Ölçek & Bölümü isteme durumları & $\mathbf{N}$ & $\begin{array}{c}\text { Sıra } \\
\text { Ortalaması }\end{array}$ & $\begin{array}{c}\text { Sira } \\
\text { Toplamı }\end{array}$ & U & $\boldsymbol{P}$ \\
\hline $\begin{array}{l}\text { Türkçe } \\
\begin{array}{l}\text { Öğretimine dair } \\
\text { yeterlikler }\end{array}\end{array}$ & $\begin{array}{l}\text { Bölüme isteyerek yerleşme } \\
\text { Bölüme istemeyerek }\end{array}$ & 208 & 140,22 & 29165,5 & 6298,5 & 0,313 \\
& yerleşme & 66 & 128,93 & 8509,5 & & \\
\hline
\end{tabular}

Tablo 6'da sınıf öğretmen adaylarının Türkçe öğretimine dair yeterliklerinin bölüme yerleşmeyi isteme durumları arasında anlamlı sayılabilecek bir fark belirlenememiştir $(p>.05)$. Ortalama puanlara bakıldığında ise bölüme isteyerek 
yerleşen sınıf öğretmen adaylarının Türkçe öğretimine dair yeterliklerinin daha yüksek olduğu görülmektedir.

\section{Tartışma, Sonuç ve Öneriler}

Araştırmadan elde edilen bulgulara göre Türkçe öğretimi dersini tamamlamış sınıf öğretmeni adaylarının Türkçe öğretimine dair kendilerini yeterli düzeyde gördükleri belirlenmiştir. Bu sonuçlar alanyazındaki öğretmen adaylarının Türkçe öğretimine dair yeterliklerini değerlendiren çalışmalarla benzerlik göstermektedir. Örneğin, Yeşiloğlu ve Özer (2017), bu çalışmaya kaynaklık eden ölçekle yaptıkları araştırmada öğretmen adaylarının Türkçe öğretimi konusunda kendilerini yeterli düzeyde buldukları görülmektedir. Aynı şekilde, Aşkın ve Demirel (2012) ile Anılan ve Kılıç (2013) yaptıkları çalışmalarda katılımcıların Türkçe öğretimi konusunda kendilerini yeterli gördükleri sonuçlarına ulaşmışlardır. Ayrıca, sınıf öğretmeni adayları Türkçe öğretiminin konuşma, dinleme, okuma, yazma, görsel okuma ve görsel sunu öğrenme alanlarına göre kendilerini yeterli görmektedirler. Burada kendilerini en çok yazma alanında, en az da konuşma alanında yeterli görmektedirler. Alanyazında öğretmen adaylarının konuşma becerilerindeki sorunlarla ilgili çalışmalarla karşılaşmaktayız. Örneğin, Akkaya (2012) yaptığı çalışmada öğretmen adaylarının konuşma ile ilgili sorunlarının olduğunu tespit etmiştir. Öğretmen adaylarının "ses, ton vurgu, telaffuz yanlışları; psikolojik (topluluk karşısında konuşamama, yakın ilişkilerde konuşamama), konuşma duraksaması, dil bilgisi kurallarını uygulayamama, bilgi eksikliği, konuşmaya odaklanamama, fiziksel nedenlerle toplumsal engellerden kaynaklanan konuşma sorunları" (Akkaya, 2012, s.419) ile mücadele ettiği belirlenmiştir. Öğretmen adaylarının bu beceride sorunlarının olması, bu alanla ilgili öğretim yapma konusunda da zayıf yönlerinin olması sonucunun ortaya çıkması da beklenen bir durumdur.

Farklı sınıf seviyelerinde bulunan Türkçe Öğretimi dersini tamamlamış sınıf öğretmeni adaylarının Türkçe öğretimine dair yeterlikleri arasında anlamlı farklar ortaya çıkmıştır. Yeni sınıf öğretmenliği lisans programı kapsamında, 2. sınıfta Türkçe Öğretimi dersini alan öğrencilerin, 3. ve 4. sinıfta bulunan öğretmen adaylarına göre kendilerini daha az yeterli hissettikleri bulgusu elde edilmiştir. Daha önce yapılan çalışmalarda da sınıf öğretmenliği programlarında okuyan öğretmen adaylarının öğrenim gördükleri sinıflara göre akademik öz-yeterliklerinin farklı olduğunu gösterdiği tespit edilmiştir. Oğuz (2012), sınıf öğretmeni adaylarıyla yaptığı araştırmada, alt sınıflarda eğitim gören adayların, 4. sınıfta okuyanlara göre yeterliklerinin daha düşük olduğu sonucuna ulaşmıştır. Bu farklılığın oluşmasında akademik yaşantılarında elde ettikleri deneyimlerin, onların yeterlik duygusunu artırdığı sonucunu çıkarabiliriz. Bir diğer çalışmada da Özder, Konedralı ve Zeki (2010) öğretmen adaylarının öğrenim hayatlarının son iki yılında özellikle uygulamaya yönelik daha fazla ders almalarının öğrencilerin akademik durumlarında pozitif etkilerin olduğu sonucuna ulaşmaktadır. Yeni sınıf öğretmenliği eğitimi programının 2. sınıf düzeyinde az sayıda uygulama içerikli ders olması, öğretmen adaylarının yeterliklerinin istenilen düzeyde olmamasına neden olmuştur denilebilir. Bu sonuçlar da öğretmen adaylarının daha çok uygulama deneyimi kazandıktan sonra yeterliklerinin arttığı sonucu ile örtüşmektedir.

Sınıf öğretmeni adaylarının Türkçe öğretimine dair yeterlikleri ile genel not ortalamaları değişkeni arasında anlamlı bir farklılık tespit edilmemiştir $(p>0,05)$. 
Ancak puan ortalamalarına bakıldı̆̆ında 2.5 ve altı genel not ortalamasına sahip öğretmen adaylarının Türkçe öğretimine dair daha düşük yeterliliğe sahip oldukları anlaşılmaktadır. Elde edilen bu sonuçlar Kahramanoğlu ve Ay (2013) tarafından yapılan çalışma ile paralellik göstermektedir. Yaptıkları çalışmanın sonucuna göre, akademik başarısı yüksek olan öğrencilerin yeterlik algılarının, nispeten ortalaması düşük öğrencilere göre yüksek olduğu sonucuna ulaşmışlardır. Bunun yanında akademik ortalamanın yeterlik algısı üzerinde herhangi bir değişiklik olmadığı sonucunu ortaya koyan çalışmalarda mevcuttur. Örneğin, Yeşiloğlu ve Özer (2017) yaptıkları araştırmada akademik başarının, Türkçe öğretimi konusunda öğretmen adaylarının yeterliklerine herhangi bir etkisinin olmadığı sonucuna ulaşmışlardır. Her ne kadar alanyazında akademik başarının etkilerinin olmadığına dair çalışmalara rastlanılsa da akademik başarının insanın özgüveni artıran bir unsur olduğu bilinmektedir.

Bir diğer değişken doğrultusunda yapılan analizde, sınıf öğretmenliği lisans eğitimi boyunca öğretmen adaylarının okudukları kitap sayısının Türkçe öğretimi yeterlikleri üzerinde etkisi olduğunu göstermiştir. 30 kitap ve daha fazla kitap okuyan sınıf öğretmen adaylarının daha az kitap okuyan öğretmen adaylarına kıyasla Türkçe öğretimine dair yeterliklerinin daha yüksek seviyede olduğu ve aralarındaki farkın da anlamlı olduğu anlaşılmaktadır. Okuma alışkanlıkları kazandırılmış öğretmen adaylarının mesleki başarılar elde ettiğine, akademik hayatında ve öz-yeterlik algısında olumlu etkiler bıraktığına dair çalışmalar alanyazında yer almaktadır (Bozpolat, 2010; Dedeoğlu ve Ulusoy, 2013; Elkatmış, 2015; Gür, 2014; Kuşdemir 2018; Kuşdemir, Bulut ve Uzun, 2020; Saracaloğlu, Karasakaloğlu ve Aslantürk, 2010; Koçak, Kurtlu, Ulaş ve Epçaçan, 2015; Ulu, 2019; Yeşiloğlu ve Özer, 2017; Yılmaz ve Benli, 2010). Bu çalışmalardan öğretmen adaylarının okuma alışkanlıklarının yüksek olması mesleki başarıları açısından önemlidir sonucunu çıkarabiliriz.

Sınıf öğretmenliği bölümünü isteyerek tercih eden öğretmen adaylarının Türkçe öğretimi yeterlik algılarının, istemeden yerleşen öğretmen adaylarına göre daha yüksek olduğu sonucuna varılmıştır. Bu sonuçlar Yeşiloğlu ve Özer (2017)'in yaptığı çalışmalardaki bulguları desteklemektedir. Araştırmacıların yaptıkları araştırmada da bölüme isteyerek yerleşen öğretmen adaylarının Türkçe öğretim yeterlikleri istemeyerek gelenlere göre yüksek çıkmıştır. Aynı şekilde Özdemir (2008) tarafından yapılan araştırmada, bölümü isteyerek seçen öğretmen adaylarının özyeterlik inançlarının, çeşitli nedenlerle öğretmenlik bölümlerini tercih etmek zorunda kalan öğretmen adaylarına göre yüksek olduğu sonucu elde edilmiştir.

Sürekli bir değişim içerisinde olan eğitim sisteminde, bu sistemin temel taşlarından biri olan öğretmen eğitiminin olduğu gibi kalması beklenemez. Bu değişime öğretmenlerin ve öğretmen adaylarının ne kadar uyum sağladığının sürekli bir değerlendirmeden geçmesi kaçınılmaz bir gerçektir. Eğitim fakültelerinde öğretmen yeterliklerine dair yapılan çalışmaların sıklaştırılması, öğretmen adaylarının programlardan maksimum fayda sağlamaları yönünde değişiklikler yapabilmek adına önemlidir. Bu nedenle sadece Türkçe Öğretimi dersi özelinde değil, içerikli derslerin çıktılarının belli aralıklarla değerlendirilmesi gerekmektedir.

Doğru bir öğretim programı oluşturmakta öğretmen eğitiminin önemli unsurlarından biridir. Çalışmada da görüldüğü gibi programda yapılan değişikliğin 
olumsuz yanları da mevcuttur. Bu konuda program içerisinde dönem ve içerik değişikliğine uğramış derslere dair araştırmaların artırılması gerekmektedir. Öğretmen adaylarının kendilerini tam anlamıyla yeterli görmeleri sağlayacak şekilde sınıf eğitimi lisans programının tekrar gözden geçirilmesi gereklidir.

Akademik başarının öğrenciler üzerinde büyük bir motivasyon kaynağ1 olduğu bilinmektedir. Akademik başarıları düşük öğrencilerin kendilerini yeterli hissetmemelerine neden olan etmenlerin daha detaylı incelemeleri yapılmalıdır.

Çeşitli becerilerin işe koşulması gereken derslerin başında gelen Türkçe Öğretimi dersinin işleyişinde, öğretmen adaylarının daha aktif olduğu derslerin planlanması gerekmektedir. Dört öğrenme alanında da en üst düzeyde yeterliğe sahip öğretmen adaylarının yetişmesi, Türkçe dersinin ilkokul sınıflarında daha etkin bir şekilde işlenmesi adına bir ön şart olarak kabul edebiliriz.

Okuma alışkanlığının en çok kazandırıldığı yer ilkokullardır. Buralarda görev yapacak öğretmenlerin okuma alışkanlıklarının düşük olması, toplumsal anlamda bir sorun olarak karşımıza çıkar. Bu nedenle öğretmen yetiştiren kurumlarda öğretmen adaylarının okuma alışkanlığına teşvik edecek gerekli imkanların oluşturulması, zengin kütüphanelerin kurulması gerekmektedir.

Genç yaşta yapılan mesleki seçimler ilerde insanların hayattan zevk alamaz bir noktaya ulaşmasına yol açabilmektedir. Bu nedenle hangi mesleğe dair üniversite eğitimi alacaklarına karar vermeye çalışan öğrencilere doğru rehberlik hizmetleri verilmelidir. Eğitim fakültelerine öğrenci seçiminde gelişmiş ülkelerde yer alan modeller örnek alınabilir. Fakülteye öğrenci seçimi merkezi yerleştirme ile değil, belli bir süre üniversitede ortak dersler alan öğrenciler arasından, mesleğe uygunluğa dair yapılacak seçme yöntemleri uygulanmalıdır. Böylece iş bulma kaygısından dolayı değil, alacağı eğitime dair daha bilgili, daha istekli öğrencilerin eğitim fakültelerine yönlendirilmesi sağlanmış olur.

\section{Teşekkür ve Bilgilendirme}

$\mathrm{Bu}$ araştırmadaki ölçeğin kullanımına izin veren Ayşe Yeşiloğlu'na teşekkür ederim.

\section{Kaynakça}

Acar, F. E. (2010). Sınıf öğretmenliği programından mezun olan öğretmenlerin

Türkçe dersine ilişkin yeterliklerinin değerlendirilmesi. Türk Ĕ̆itim Bilimleri Dergisi, 8(1), 89-115.

Akkaya, A. (2012). Öğretmen adaylarının konuşma sorunlarına ilişkin görüşleri. Mustafa Kemal Üniversitesi Sosyal Bilimler Enstitüsü Dergisi, 9(20), 405420.

Akyol, H. (2016). Türkçe öğretim yöntemleri. Ankara: Pegem Akademi.

Anılan, H. ve Kılıç, Z. (2013). Sınıf öğretmeni adaylarının Türkçe öğretimi dersine ve Türkçe öğretimi konusundaki yeterliliklerine ilişkin görüşleri. Adıyaman Üniversitesi Sosyal Bilimler Enstitüsü Dergisi, 6(13), 2-48. https:// doi.org/10.14520/adyusbd.491

Aşkın, İ. ve Demirel, M. (2012). Sınıf öğretmeni adaylarının Türkçe Öğretimi yeterliklerine ilişkin görüşleri. Ĕ̆itim ve Öğretim Araştırmalan Dergisi, 1(3), 178189.

Babaoğlan, E. ve Yılmaz, Ş. (2010). Sınıf öğretmenlerinin kaynaştırma eğitimindeki yeterlikleri. Kastamonu Ĕ̆itim Dergisi, 18(2), 345-354. 
Baştuğ , M. (2016). Classroom teachers' feelings and experiences in teaching early reading and writing: A phenomenological study. Education, 44(6), 736-750. https:/ / doi.org/10.1080/03004279.2015.1009927

Bektaş, M., Aydın, E. ve Ayvaz, A. (2015). Sınıf öğretmeni adaylarının gelecekteki mesleki yeterliklerine yönelik görüşleri. Sakarya University Journal of Education, 5(2), 174-192. https:/ / doi.org/10.19126/suje.35440

Bektaş, M, Ayvaz-Can, A. ve Çalıkoğlu, E . (2019). Sınıf öğretmeni adaylarının mesleki beceri öğretmen yeterliklerinin incelenmesi. Trakya Eğitim Dergisi, 9(4), 771-790. https:/ / doi.org/10.24315/tred.526533

Berkant, A. G. H. G. ve Ekici, G. (2007). Sınıf öğretmeni adaylarının fen öğretiminde öğretmen öz yeterlik inanç düzeyleri ile zekâ türleri arasındaki ilişkinin değerlendirilmesi. Çukurova Üniversitesi Sosyal Bilimler Enstitüsü Dergisi, 16(1), 113-132.

Bozpolat, E. (2010). Öğretmen adaylarının okuma alışkanlığına ilişkin tutumlarının değerlendirilmesi (Cumhuriyet Üniversitesi Eğitim Fakültesi örneği). Zeitschrift für die Welt der Türken/Journal of World of Turks, 2(1), 411-428.

Buldu, M. (2014). Öğretmen yeterlik düzeyi değerlendirmesi ve mesleki gelişim eğitimleri planlanması üzerine bir öneri. Milli Eğitim Dergisi, 43(204), 114- 134.

Büyüköztürk, Ş., Çakmak, E. K., Akgün, Ö. E., Karadeniz, Ş. ve Demirel, F. (2016). Bilimsel araştırma yöntemleri (22. baskı). Ankara: Pegem Akademi. https:// doi.org/10.14527/9789944919289

Cerit, Y. and Özdemir, T. (2015). The relationship between classroom teachers' perceptions of workload and intent to leave. International Journal of Human Sciences, 12(2), 626-637. https:/ / doi.org/10.14687/ijhs.v12i2.3121

Çapri, B. ve Çelikkaleli, Ö. (2008). Öğretmen adaylarının öğretmenliğe ilişkin tutum ve mesleki yeterlik inançlarının cinsiyet, program ve fakültelerine göre incelenmesi. İnönü Üniversitesi Eğitim Fakültesi Dergisi, 9 (15), 33-53.

Çelik, Ö., Yorulmaz, A. ve Çokçalışkan, H. (2019). Öğretmen genel yeterlikleri açısından sınıf öğretmenleri ve öğretmen adaylarının kendilerini değerlendirmeleri. Eskişehir Osmangazi Üniversitesi Sosyal Bilimler Dergisi, 20, 203-215.

Çetin, B. (2018). Sınıf öğretmeni adaylarının hayat bilgisi öğretimi dersine yönelik tutumları. Ahi Evran Üniversitesi Kırşehir Eğitim Fakültesi Dergisi, 19(1), 640-651. https:/ / doi.org/10.29299/kefad.2018.19.018

Darling-Hammond, L. (2000). Teacher quality and student achievement. Education policy analysis archives, 8(1), 1-44. https:/ / doi.org/10.14507/epaa.v8n1.2000

Dedeoğlu, H. ve Ulusoy, M. (2013). Sınıf öğretmeni adaylarının okuma tutumları. Okuma Yazma Eğitimi Araştırmaları, 1(2), 80-88.

Donmuş, V., Akpunar, B. ve Eroğlu, M. (2017). Öğretmen adaylarının akademik özyeterlikleri ve mesleki kaygıları arasındaki ilişkinin incelenmesi. Mustafa Kemal Üniversitesi Sosyal Bilimler Enstitüsü Dergisi, 14(37).

Elkatmış, M. (2015). Sınıf öğretmeni adaylarının okuma ilgi ve alışkanlıkları. Kastamonu Üniversitesi Kastamonu Eğitim Dergisi, 23(3), 12231240. 
Erdem, A. ve Bayraktar, A. (2019). Öğretmen adaylarının Türkçe öğretimi uygulamalarına ilişkin görüşleri. Ana Dili Ĕ̆itimi Dergisi, 7(1), 11-27. https:// doi.org/10.16916/aded.416703

Evran Acar, F. (2010). Sınıf öğretmenliği programından mezun olan öğretmenlerin Türkçe dersine ilişkin yeterliklerinin değerlendirilmesi. Türk Ĕ̆itim Bilimleri Dergisi, 8(1), 89-115.

Goe, L. and Stickler L. M. (2008). Teacher quality and student achivement: making the most of recent research. National Comprehensive Center for Teacher Quality.

Gök, B. ve Erdoğan, T. (2009). Sınıf öğretmeni adaylarının yeni Türkçe öğretim programındaki ölçme ve değerlendirme yöntemlerini kullanma düzeyleri. Çukurova Üniversitesi Sosyal Bilimler Enstitüsü Dergisi, 18 (1), 233-246.

Gür, T. (2014). Öğretmen adaylarının okuma ve boş zaman değerlendirme alışkanlıkları. Zeitschrift Für Die Welt Der Türken/Journal Of World Of Turks, 6(1), 161-180.

Güven, B. ve Ersoy, E. (2007). Sınıf öğretmeni adaylarının Hayat Bilgisi ve Sosyal Bilgiler Öğretimi I dersine ilişkin öz yeterlik algıları ve bilişsel tutumlarının belirlenmesi. Pamukkale Üniversitesi Ĕ̆itim Fakültesi Dergisi, 21, 15-32.

Hacıömeroğlu, G. ve Şahin-Taşkın, Ç. (2010). Sınıf öğretmeni adaylarının matematik öğretimi yeterlik inançları. Uludağ Üniversitesi Ĕ̆itim Fakültesi Dergisi, 23(2), 539-555.

Gencel, İ. E. (2013). Öğretmen adaylarının yaşam boyu öğrenme yeterliklerine yönelik alg1ları. Eğitim ve Bilim, 38(170), 237-252.

Jaquith, A., Mindich, D., Wei, R. C. and Darling-Hammond, L. (2010). Teacher professional learning in the United States: Case studies of state policies and strategies. Learning Forward

Kahramanoğlu, R. ve Ay, Y. (2013). Sınıf öğretmeni adaylarının özel alan yeterlik algılarının çeşitli değişkenler açısından incelenmesi. Uluslararası Türkçe Edebiyat Kültür Ĕ̈itim (TEKE) Dergisi, 2(2), 285-301.

Kara, N., Demir, M.K., Arcagök, S. ve Şahin, Ç. (2018). Sınıf öğretmenlerinin mesleki gelişimleri açısından sınıf eğitimi lisans programının yeterliliği. Electronic Turkish Studies, 13(19), 1061-1082. https:// doi.org/10.7827/TurkishStudies.14043

Karasakaloğlu, N. ve Saracaloğlu, A. S. (2009). Sınıf öğretmeni adaylarının Türkçe derslerine yönelik tutumları, akademik benlik tasarımları ile başarıları arasındaki ilişki. Yüzüncü Yıl Üniversitesi Eğitim Fakültesi Dergisi, 6(1), 343-362.

Koçak, B., Kurtlu, Y., Ulaş, A. ve Epçaçan, C. (2015). Sınıf öğretmeni adaylarının eleştirel düşünme düzeyleri ve okumaya yönelik tutumları arasındaki ilişki. Ekev Akademi Dergisi, 61, 211-228.

Kuşdemir, Y. (2018). Analysis of prospective classroom teachers'attitudes towards reading book. European Journal of Education Studies, 5(8), 207-219.

Kuşdemir, Y., Bulut, P. ve Uzun, E. B. (2020). Okuma kültürü üzerine bir inceleme: Öğretmen adayları örneği. Gençlik Araştırmaları Dergisi, 8 (21) , 74-95

MEB Öğretmen Yetiştirme ve Eğitimi Genel Müdürlüğü (2006). Öğretmenlik mesleği genel yeterlilikleri. 10 Eylül 2020 tarihinde https:/ / oygm.meb.gov.tr/meb_iys_dosyalar/2017_12/11115355_YYRETMEN LYK_MESLEYY_GENEL_YETERLYKLERY.pdf adresinden alınmıştır. 
MEB Öğretmen Yetiştirme ve Eğitimi Genel Müdürlüğü (2006). Sinıföğretmeni özel alan yeterlikleri. 04 Eylül 2020 tarihinde http:/ /oygm.meb.gov.tr/meb_iys_dosyalar/2017_11/06160532_8YYretmen_Yeterlikleri_KitabY_sYnYf_YYretmenliYi_alan_yeterlikleri_ilkYYre tim_parYa_11.pdf adresinden alınmıştır.

Odabaşı, F., Çoklar, A.N., Kıyıc1, M. ve Akdoğan, E.P. (2005). İlköğretim birinci kademede web üzerinden ders işlenebilirliği. The Turkish Online Journal of Educational Technology, 4(4), 182-190.

Oğuz, A. (2012). Sınıf öğretmeni adaylarının akademik öz yeterlik inançları. Anadolu Journal of Educational Sciences International, 2(2), 15-28.

Okur, S. (2011). Türkçe ve sınıf öğretmeni adaylarının Türkçe dersi öğretim araçlarındaki okuma metinlerini özetleme becerileri. Yayınlanmamış Yüksek Lisans Tezi.

Onan, B. ve Kan, M.O. (2018). İlk okuma yazma ve Türkçe öğretimi. Ankara: Nobel Akademik Yayıncılık.

Özdemir, C. ve Erdoğan, T. (2017). Sınıf öğretmeni adaylarının ilkokuma ve yazma öğretimine ilişkin öz yeterlik inançlarının belirlenmesi. Abant İzzet Baysal Üniversitesi Ĕ̆itim Fakültesi Dergisi, 17(1), 314-331. https://doi.org/10.17240/aibuefd.2017.17.28551-304637

Özdemir, S. M. (2008). Sınıf öğretmeni adaylarının öğretim sürecine ilişkin özyeterlik inançlarının çeşitli değişkenler açısından incelenmesi. Kuram ve Uygulamada Ĕ̆itim Yönetimi Dergisi, 14(2), 277-306.

Özer, B. ve Gelen, İ. (2014). Öğretmenlik mesleği genel yeterliklerine sahip olma düzeyleri hakkında öğretmen adayları ve öğretmenlerin görüşlerinin değerlendirilmesi. Mustafa Kemal Üniversitesi Sosyal Bilimler Enstitüsü Dergisi, 5(9), 39-55 .

Saracaloğlu, A.S., Karasakaloğlu, N. ve Aslantürk, E. (2010). Sınıf öğretmeni adaylarının okuma ilgi ve alışkanlıklarının karşılaştırılması (Adnan Menderes Üniversitesi ve Uludağ Üniversitesi Örneği). Çukurova Üniversitesi Sosyal Bilimler Enstitüsü Dergisi, 19(3), 461.484.

Sünbül, A. M. (2011). Öğretim İlke ve Yöntemleri (5. Baskı). Konya, Türkiye: Eğitim Kitabevi.

Şahin, A. (2011). Öğretmen Algılarına Göre Etkili Öğretmen Davranışları. Journal of Kirsehir Education Faculty, 12(1), 239-259.

Şişman, M. ve Acat, M. B. (2003). Öğretmenlik uygulaması çalışmalarının öğretmenlik mesleğinin algılanmasındaki etkisi. Fırat Üniversitesi Sosyal Bilimler Dergisi, 13(1), 235-250.

Taşgın, A. ve Sönmez, S. (2010). Öğretmenlik mesleği genel yeterliklerinin sınıf öğretmenleri ve sınıf öğretmeni adaylarının görüşlerine göre değerlendirilmesi (Öğretme ve öğrenme süreci yeterlikleri-öğrenmeyi, gelişimi izleme ve değerlendirme yeterlikleri). Yayımlanmamış Yüksek Lisans Tezi, Erzurum: Atatürk Üniversitesi Sosyal Bilimler Enstitüsü.

Ulu, H. (2019). Examining the relationships between the attitudes towards reading and reading habits, metacognitive awarenesses of reading strategies, and critical thinking tendencies of pre-service teachers. International Journal of 
Contemporary Educational Research, 6(1), 169-182.

https:/ / doi.org/10.33200/ijcer.549319

Yeşiloğlu, A. ve Özer, M. (2017). Sınıf öğretmenliği son sınıf öğrencilerinin Türkçe öğretimi konusundaki yeterliliklerinin değerlendirilmesi. Turkish Studies,

12(6), 863-880. https:/ / doi.org/10.7827/TurkishStudies.11497

Yılmaz, M. ve Benli, N. (2010). Sınıf öğretmeni adaylarının okuma alışkanlığına yönelik tutumlarının bazı değişkenlere göre incelenmesi. Erzincan Eğitim Fakültesi Dergisi, 12(1), 281-291.

Yüksek Öğretim Kurulu (2018). Programların güncellenme gerekçeleri, getirdiği yenilikler ve uygulama esasları. Ankara. 09 Eylül 2020 tarihinde https://www.yok.gov.tr/Documents/Kurumsal/egitim_ogretim_dairesi/Ye ni-Ogretmen-Yetistirme-Lisans-

Programlari/AA_Sunus_\%20Onsoz_Uygulama_Yonergesi.pdf adresinden alınmıştır.

\section{Summary}

\section{Introduction}

The importance of teacher qualifications in sustaining quality instructional activities is undeniable. Although teachers' roles and responsibilities have changed to respond to the ever-changing needs of the times, teachers' importance in educational services has not declined; on the contrary, it continues to increase with each passing day (Akyol, 2016; Baştuğ, 2016; Odabaşı, Çoklar, Kıyıcı, \& Akdoğan, 2005; Onan \& Kan, 2018; Özer \& Gelen, 2008). Official organizations and institutions have, throughout history, conducted various studies on what constitutes teacher qualifications and continue to do so from time to time. The most recent of these studies was The General Qualifications for the Teaching Profession conducted in 2006 by the joint participation of Turkey's Council of Higher Education, Ministry of National Education (MoNE), NGOs, and other field specialists (MoNE, 2006). The General Qualifications for the Teaching Profession published by the General Directorate for Teacher Training and Development defines teacher qualifications as "the necessary knowledge, skills, and attitudes in order to realize the teaching profession in an effective and efficient manner" (p. 4). Updated regularly, this document specifies what knowledge and skills, and in what areas, teachers need to possess. Similarly, the Content Area Qualifications developed by MoNE defined what proficiencies future primary, middle, and high school teachers were required to possess depending on their specific content area. These content area qualifications are grouped under four separate categories, namely (i) qualification area, (ii) scope, (iii) qualifications, and (iv) performance indicators (MoNE, 2017). Upon a more thorough investigation of content area qualifications, primary school teachers are required by the nature of their profession to develop a greater number of special field qualifications than teachers of other areas.

This study, therefore, seeks to examine preservice primary school teachers' (PPSTs)' Turkish language teaching proficiencies according to multiple variables. The sample group was composed of 274 preservice teachers enrolled in the Faculty of Education's Department of Primary School Teaching of Çanakkale Onsekiz Mart 
University during the 2019-2020 academic year and have completed the required 3credit Turkish Language Teaching class.

Accordingly, answers to the following questions have been sought:

1. What do the Turkish language teaching proficiency levels of PPSTs who have completed their required Turkish language education class?

2. What do the proficiency levels of PPSTs according to subfields (speaking, reading, writing, listening, visual reading and presentation) of Turkish language teaching?

3. Does one's year of study affect the Turkish language teaching proficiency levels of PPSTs who have completed their required Turkish language education class in a meaningful way?

4. Does GPA affect the Turkish language teaching proficiency levels of PPSTs who have completed their required Turkish language education class in a meaningful way?

5. Does the number of books read during one's years as an undergraduate affect the Turkish language teaching proficiency levels of PPSTs who have completed their required Turkish language education class in a meaningful way?

6. Does whether one was intrinsically motivated to study in the department of primary school education affect the Turkish language teaching proficiency levels of PPSTs in a meaningful way?

\section{Method}

This study employed a descriptive survey model to assess PPSTs' Turkish language teaching qualifications. The population consisted of preservice teachers enrolled in Çanakkale Onsekiz Mart University's Faculty of Education during the 2019-2020 academic year. The sample, however, was made up of 274 preservice teachers enrolled in the Faculty of Education's Department of Primary School Teaching in the same university. Turkish Language Teaching Proficiency Scale developed by Yeşiloğlu and Özer (2017) was employed to identify how PPSTs perceived their own qualifications. This 5-point Likert-type scale contained a total of 60 items measuring five basic teaching aspects, namely, listening, speaking, reading, writing, and visual literacy/visual presentation. No negative items were included in the scale. Cronbach's Alpha (a) for the scale was 0.98. Data were collected during the spring semester of the 2019-2020 academic year by the researcher himself, who, after informed participants that their participation in the study was purely voluntary and that the results would be used for scientific purposes, gave instructions on how to complete the scale. The scale took approximately 20 minutes to complete. SPSS 20.00 was used to analyze the data collected in this study. PPSTs own beliefs regarding their Turkish language teacher qualifications. The mean and standard deviation values were calculated in order to depict descriptive numerical values during the data's analysis. The scale was assessed based on a score of 300. A mean score of 11.80 indicated highly inadequate, $1.81-2.60$ inadequate, 2.61-3.40 partially adequate, 3.41-4.20 adequate, and 4.21-5.00 highly adequate. 


\section{Results}

This section presents findings pertaining to PPSs' Turkish language teaching qualifications.

1. PPSTs identified their Turkish language teachinh proficiency levels as being adequate.

2. A significant difference was found to exist between PPSTs' Turkish language teaching qualifications and their year of study $\left(X^{2}=8.360 ; p<0.05\right)$. Compared to third- and fourth-year PPSTs, second-year PPSTs were less proficient in teaching Turkish; this difference was statistically significant.

3. No meaningful difference was found between GPA and PPSTs' Turkish language teaching qualification $(p>0.05)$. Upon subsequent review, however, we found that PPSTs with a GPA of 2.5 and below had lower Turkish language teaching proficiency levels than those with higher GPAs.

4. A significant difference was found between PPSTs' Turkish language teaching qualifications and the number of books they read during their years as undergraduates $\left(X^{2}=8.890 ; p<0.05\right)$. PPSTs who had read 30 or more books were found to have higher Turkish language teaching proficiency levels compared to those who had read fewer books; this difference was statistically significant.

\section{Discussion}

The study's findings concluded that PPSTs who had completed their required Turkish language teaching class were adequately proficient in teaching Turkish. The findings resemble those of other studies in the literature assessing PPSTs' Turkish language teaching qualifications. Yeşiloğlu and Özer (2017), in whose study the scale used in this research was developed, found that preservice teachers' Turkish language qualifications were adequate. In a similar vein, both the studies by Aşkın and Demirel (2012) and Anılan and Kılıç (2013) concluded that their participants considered themselves to be adequate in teaching Turkish.

Significant differences emerged in PPSTs' Turkish language teaching proficiency levels depending on their year of university study. Specifically, those who had taken this class during their second year considered themselves to be less proficient compared to those who had taken it during their third and fourth years. Previous studies have similarly found that PPSTs had different perceptions of their academic self-efficacy levels based on their grade level. In her study with PPSTs, Oğuz (2012) found that students of lower grade levels perceived their self-efficacy levels to be lower than fourth-year students did. One possible explanation for this difference is that as students' academic experiences increase, their sense of selfefficacy also increases. According to Özder, Konedralı, and Zeki (2010), the fact that preservice teachers have more classes dealing with practical application during the last two years of their academic careers has a positive impact on their academic performance. These findings are consistent with the finding that preservice teachers' proficiency levels begin to witness a significant increase only after gaining practical experience.

GPA was found not to have any significant impact on the differences in PPSTs' Turkish language teacher proficiency levels $(p>0.05)$. Upon further examination of mean scores, it was found that PPSTs with a GPA of 2.5 or less were less proficient in teaching Turkish than those with a higher GPA. This finding is in 
line with that reported in the study conducted by Kahramanoğlu and Ay (2013), who found that high-achieving students perceived their proficiency levels to be relatively higher than those with lower GPAs. Similarly, several other studies have concluded that GPA does not affect perceived proficiency. For example, Yeşiloğlu and Özer (2017) found that academic performance had no effect on preservice teachers' proficiency levels. That said, regardless of however many studies may have concluded that academic performance has no effect on proficiency levels, it is still known as a factor that increases individuals' self-confidence.

Another variable examined in this study, namely, the number of books read during one's undergraduate years, was found to have a statistically significant impact on PPSTs' Turkish language teaching proficiency levels. Specifically, the PPSTs who had read at least 30 books had higher Turkish language teaching proficiency levels than those who had read fewer than 30 books. Indeed, several studies have found that preservice teachers who are frequent readers perform better academically, are more successful in their professions, and have higher self-efficacy perceptions (Bozpolat, 2010; Elkatmış, 2015; Gür, 2014; Saracaloğlu, Karasakaloğlu, \& Aslantürk, 2010; Koçak, Kurtlu, Ulaş, \& Epçaçan, 2015; Yeşiloğlu \& Özer, 2017, Yilmaz \& Benli, 2010).

PPSTs who were intrinsically motivated to study primary school education perceived their Turkish language teaching proficiency levels to be higher than those who had chosen it due to some extrinsic obligation. The findings of Yeşiloğlu and Özer (2017) were similar in this regard; the preservice teachers who had been intrinsically motivated to choose their field of study were more proficient in teaching Turkish than those who had chosen it for other reasons. Similarly, Özdemir (2008) found that preservice teachers who had chosen to study in the department of education for intrinsic reasons had higher self-efficacy beliefs than those who had felt obligated to choose it for whatever reason.

\section{Pedagogical Implications}

It is unreasonable to expect that teacher education, being one of the cornerstones of the educational system, will remain the same as changes are constantly made to the education system. These changes inevitably necessitate that both preservice and licensed teachers should be regularly assessed to determine the degree that they are able to adapt to these changing realities. It is therefore critical that studies on teacher qualifications conducted in faculties of education should be increased and that changes should be made to curricula so that preservice teacher may obtain the maximum benefit from their educational programs. Consequently, the outcomes of all practical application classes, and not only students' Turkish Language Teaching class, should be subjected to assessment.

Teacher education is one of the most important elements in successfully devising an effective curriculum. As this study has revealed, there are negative consequences of making curricular changes. Therefore, further studies examining classes that have been subjected to changes in their content and the year in which they are studied are needed. In fact, it is necessary to review the primary school education curriculum implemented in faculties of education so that preservice teachers may consider themselves fully qualified in their field. 
Since academic performance has been established as a veritable source of motivation for students, factors causing lower-achieving students to consider themselves inadequate should be examined with more in-depth studies.

Since primary school is the easiest period for individuals to develop a reading habit, teachers who does not have a reading habit have the potential to cause negative social ramifications. As a result, institutions invested in teacher education should encourage preservice teachers to develop such a habit by offering them the necessary facilities and opportunities, like establishing libraries rich in content.

Since deciding upon a career while still young may impair one's ability to derive true pleasure from life, effective vocational counseling should be provided to those students trying to decide what field of study they should pursue during their university education. Models used to select students for entry into faculties of education employed in developed countries may be taken as examples. For example, instead of a central placement system, students could be selected for inclusion in specific faculties based on the extent of how well their goals fit those of the faculty after having taken a certain number of general education classes in their university. This will allow a greater number of more intrinsically motivated students to be directed to faculties of education instead of students choosing to study education out of anxiety to find a profession.

\section{Araştırmanın Etik İzinleri}

Yapılan bu çalışmada "Yükseköğretim Kurumları Bilimsel Araştırma ve Yayın Etiği Yönergesi" kapsamında uyulması belirtilen tüm kurallara uyulmuştur. Yönergenin ikinci bölümü olan “Bilimsel Araştırma ve Yayın Etiğine Aykırı Eylemler” başlı̆̆ı altında belirtilen eylemlerden hiçbiri gerçekleştirilmemiştir.

Etik kurul izin bilgileri

Etik değerlendirmeyi yapan kurul adı =Çanakkale Onsekiz Mart Üniversitesi

Etik değerlendirme kararının tarihi $=04.05 .2020$

Etik değerlendirme belgesi sayı numarası=2020/74

\section{Author's Biodata/ Yazar Bilgileri}

Yahya Han ERBAŞ Çanakkale Onsekiz Mart Üniversitesi, Eğitim Fakültesi, Eğitim Bilimleri Bölümü, Eğitimin Felsefi, Sosyal ve Tarihi Temelleri Anabilim Dalı'nda Dr. Öğretim Üyesi olarak çalışmaktadır. Akademik çalışma alanları; ilkokuma ve yazma öğretimi, Türkçe öğretimi, öğretmen eğitimi, çokkültürlü eğitim ve eğitimde nitel araştırma yöntemleridir.

Yahya Han Erbaş is an assistant professor in the Department of Philosophical, Social, and Historical Foundations of Education at Çanakkale Onsekiz Mart University. His research interests include first reading and writing education, teaching Turkish in elementary education, teacher education, multicultural education and qualitative research methods in education. 